\title{
An interdisciplinary consensus on the management of bone metastases from renal cell carcinoma
}

\author{
Viktor Grünwald (10 ${ }^{1 *}$, Berit Eberhardt ${ }^{2,3}$, Axel Bex ${ }^{4}$, Anne Flörcken ${ }^{5}$, Thomas Gauler ${ }^{6}$, \\ Thorsten Derlin ${ }^{7}$, Martin Panzica ${ }^{8}$, Hans Roland Dürr ${ }^{9}$, Knut Achim Grötz ${ }^{10}$, \\ Rachel H. Giles $\mathbb{1}^{3,11}$, Christian von Falck ${ }^{12}$, Anno Graser ${ }^{13}$, Alexander Muacevic ${ }^{14}$ \\ and Michael Staehler (10 ${ }^{15}$
}

Abstract | Bone is a major site of haematogenous tumour cell spread in renal cell carcinoma (RCC), and most patients with RCC will develop painful and functionally disabling bone metastases at advanced disease stages. The prognosis of these patients is generally poor and the treatment is, therefore, aimed at palliation. However, RCC-associated bone metastases can be curable in select patients. Current data support a multimodal management strategy that includes wide resection of lesions, radiotherapy, systemic therapy, and other local treatment options, which can improve quality of life and survival. Nevertheless, the optimal approach for metastatic bone disease in RCC has not yet been defined and practical recommendations are rare.

To improve the management and outcomes of patients with RCC and bone metastases, the International Kidney Cancer Coalition and the interdisciplinary working group on renal tumours of the German Cancer Society convened a meeting of experts with a global perspective to perform an unstructured review and elaborate on current treatment strategies on the basis of published data and expertise. The panel formulated recommendations for the diagnosis and treatment of patients with RCC and metastasis to the bone. Furthermore, the experts summarized current challenges and unmet patient needs that should be addressed in the future.

Haematogenous spread to the bone is common in patients with renal cell carcinoma (RCC) ${ }^{1}$. Around onethird of patients with metastatic RCC are diagnosed when they already have bone metastases and another third of patients will develop them throughout their future disease course $\mathrm{e}^{2}$. Before the introduction of targeted therapy to clinical practice in RCC, the rate of skeletal-related events (SREs), defined as pathological fractures, radiotherapy, surgery, neural compression, or hypercalcaemia, was $74-85 \%{ }^{3}$. Since the use of targeted antiangiogenic therapy in patients with advanced disease and the resulting extended overall survival, bone metastases have become even more prevalent ${ }^{2-5}$. Owing to their predominantly osteolytic nature, bone metastases in RCC can be associated with severe morbidity and predispose patients to skeletal complications $s^{1-4}$. Local treatments include radiotherapy in $\sim 80 \%$ of patients and orthopaedic surgery in $\sim 30 \%$ of patients ${ }^{6}$. However, pain is often poorly managed, indicating a need for improved treatment strategies ${ }^{1,7,8}$. Importantly, some patients are candidates for curative treatment. A multidisciplinary management approach is warranted to yield optimal outcomes, as no common diagnostic and therapeutic standard currently exists and clinical guidelines provide limited information on how to manage bone metastases from $\mathrm{RCC}^{2,9-12}$. A review of local therapies for RCC metastases in general revealed the poor evidence base for the treatment of bone metastases ${ }^{13}$.

In this Expert Consensus Document, we summarize the consented recommendations for the diagnosis and treatment of patients with RCC and metastasis to the bone. Furthermore, we outline current challenges and unmet patient needs that should be addressed in the future.

\section{Methods}

The International Kidney Cancer Coalition (IKCC) an independent global network of patient organizations with a focus on kidney cancer - and the interdisciplinary working group on renal tumours of the German Cancer Society met in Berlin, Germany, to elaborate 
recommendations on the basis of the available literature and experience. Invitees included a multidisciplinary panel of clinical experts from various institutions with ample experience in the treatment of patients with kidney cancer. The objective of the meeting was to identify unmet patient needs and to provide guidance for diagnosis and treatment of bone metastases from RCC in routine practice according to the literature, enhanced by expert opinion after thorough discussion. The different sections of this Expert Consensus Document, which describe the reported data, are followed by summaries of the available evidence, in which each point has been classified according to the level of evidence (LoE) of the available data (TABLE 1). Specific recommendations according to the panel's position are then listed, and outstanding issues and patient needs are summarized.

\section{Epidemiology of RCC bone metastases}

Lung lesions are the most frequent manifestation of metastases in patients with $\mathrm{RCC}^{14}$. The bones are the second most common site for metastases from $\mathrm{RCC}^{4,8,9,14,15}$, and occurrence of bone metastases has been reported in $35-40 \%$ of patients with advanced RCC $\mathrm{R}^{9,12,16,17}$. These metastases are predominantly found in the pelvis, sacrum, spine, and proximal extremities ${ }^{18}$ and are predominantly osteolytic lesions (79\% osteolytic, 7\% osteoblastic, and $13 \%$ mixed lesions $)^{15}$ (FIG. 1). A study that included data from $>1,800$ patients found that $31 \%$ of patients had bone metastases at the time of RCC diagnosis, whereas $68 \%$ developed bone metastasis at a median period of 25 months throughout the course of their disease ${ }^{15}$. Most patients presented with multiple bone metastases (71\%).

The median overall survival after diagnosis of RCC bone metastases ranges from 12 months to 28 months ${ }^{19,20}$. A retrospective study from 2016 analysed the association between the onset of bone metastases and outcome in 82 patients with RCC and bone metastases treated with sunitinib $^{21}$. The time to clinical progression on sunitinib

\footnotetext{
Author addresses

${ }^{1}$ Department of Hematology, Hemostasis, Oncology and Stem Cell Transplantation,

Hannover Medical School, Hannover, Germany.

'Uronauten e.V., Berlin, Germany.

${ }^{3}$ International Kidney Cancer Coalition, Duivendrecht, Netherlands.

${ }^{4}$ Division of Surgical Oncology, Department of Urology, The Netherlands Cancer Institute, Amsterdam, Netherlands.

${ }^{5}$ Department of Hematology, Oncology, and Tumor Immunology, Charité University

Medicine Berlin, Berlin, Germany.

${ }^{6}$ Westdeutsches Tumorzentrum, Universitätsklinik Essen, Essen, Germany.

'Department of Nuclear Medicine, Hannover Medical School, Hannover, Germany.

${ }^{8} \mathrm{Clinic}$ of Trauma Surgery, Medical School Hannover, Hannover, Germany.

${ }^{9}$ Orthopaedic Oncology, Department of Orthopaedic Surgery, Ludwig-Maximilians

University Munich, Munich, Germany.

${ }^{10}$ Department of Oral and Maxillofacial Surgery of the Dr Horst Schmidt Clinic,

Wiesbaden, Germany.

${ }^{11}$ Nephrology and Hypertension, University Medical Center Utrecht, Utrecht,

Netherlands.

${ }^{12}$ Department of Diagnostic and Interventional Radiology, Hannover Medical School,

Hannover, Germany.

${ }^{13}$ Radiologie München, Munich, Germany.

${ }^{14}$ European Cyberknife Center Munich-Großhadern, Munich, Germany.

${ }^{15}$ Department of Urology, Ludwig-Maximilians University Munich, Munich, Germany.
}

\begin{tabular}{|l|l|}
\hline $\begin{array}{l}\text { Table } 1 \text { | Levels of evidence } \\
\text { Level of } \\
\text { evidence }\end{array}$ & Description \\
\hline 1 & $\begin{array}{l}\text { Large RCT with low potential for bias; } \\
\text { meta-analyses of well-conducted RCTs }\end{array}$ \\
\hline 2 & $\begin{array}{l}\text { Other randomized trials or } \\
\text { meta-analyses of such trials or of RCTs } \\
\text { with demonstrated heterogeneity }\end{array}$ \\
\hline 3 & \begin{tabular}{l} 
Prospective cohort studies \\
\hline 4
\end{tabular} \\
\hline 5 & $\begin{array}{l}\text { Retrospective cohort studies or case- } \\
\text { control studies }\end{array}$ \\
\hline 5 & $\begin{array}{l}\text { Studies without control group, case } \\
\text { reports, experts opinions }\end{array}$ \\
\hline $\begin{array}{l}\text { This table is adapted from a table in the European Society } \\
\text { for Medical Oncology (ESMO) Clinical Practice Guidelines } \\
\text { Standard Operating Procedures }{ }^{108} \text { that is used for evidence } \\
\text { grading for the ESMO Clinical Practice Guidelines. } \\
\text { RCT, randomized controlled trial. }\end{array}$ \\
\hline
\end{tabular}

treatment was similar for patients with synchronous and metachronous bone lesions, but overall survival was longer for patients with metachronous bone lesions than for those with synchronous lesions (38.5 months (95\% CI 15-62) versus 21.1 months (95\% CI 16-26.2); $P=0.001)$, indicating a differential role of immediate and subsequent occurrence of bone metastases in RCC. The prognostic role of the number of bone metastases from RCC has been retrospectively analysed in 300 patients ${ }^{22}$. In this work, the number of bone metastases was associated with overall survival. Patients with $1,2-5$, or $>5$ bone metastases had a median overall survival of 28 months, 18 months, or 9 months, respectively. Patients with a solitary synchronous bone metastasis had the longest survival (40 months), a finding that is supported by other studies ${ }^{23,24}$. A long interval ( $\geq 24$ months) from diagnosis of RCC to onset of bone metastases, having a solitary bone lesion, and the absence of extraosseous metastases are associated with prolonged survival ${ }^{20,23}$. A retrospective analysis of data from 94 patients suggested five risk factors to predict prognosis of patients with RCC and bone metastases: sarcomatoid differentiation of the primary tumour $(P=0.001)$, spinal involvement $(P=0.003)$, extraosseous metastasis $(P=0.021)$, increased alkaline phosphatase levels $(>1.5$ times the upper limit of normal; $P=0.0003)$, and increased C-reactive protein levels $(>0.3 \mathrm{mg} / \mathrm{dl} ; P=0.018)^{25}$.

\section{Diagnostic evaluation of RCC bone metastases}

Early diagnosis of bone metastases is essential for reducing morbidity and improving outcome ${ }^{2,26}$, for which appropriate imaging is needed. However, current imaging techniques are limited by their sensitivity (bone scintigraphy) and availability or costs (whole-body MRI). Current guidelines suggest imaging in the presence of symptoms only, for example, bone pain or fracture ${ }^{11}$, thus, restricting diagnosis to patients with debilitating or complicating metastases. In the absence of appropriate techniques, adequate follow-up monitoring with clinical surveillance is important in the management of patients with RCC. Of note, contemporary surveillance measures consist of routine images of the thorax and abdomen, which do not capture extremities and the neck, which needs to be 

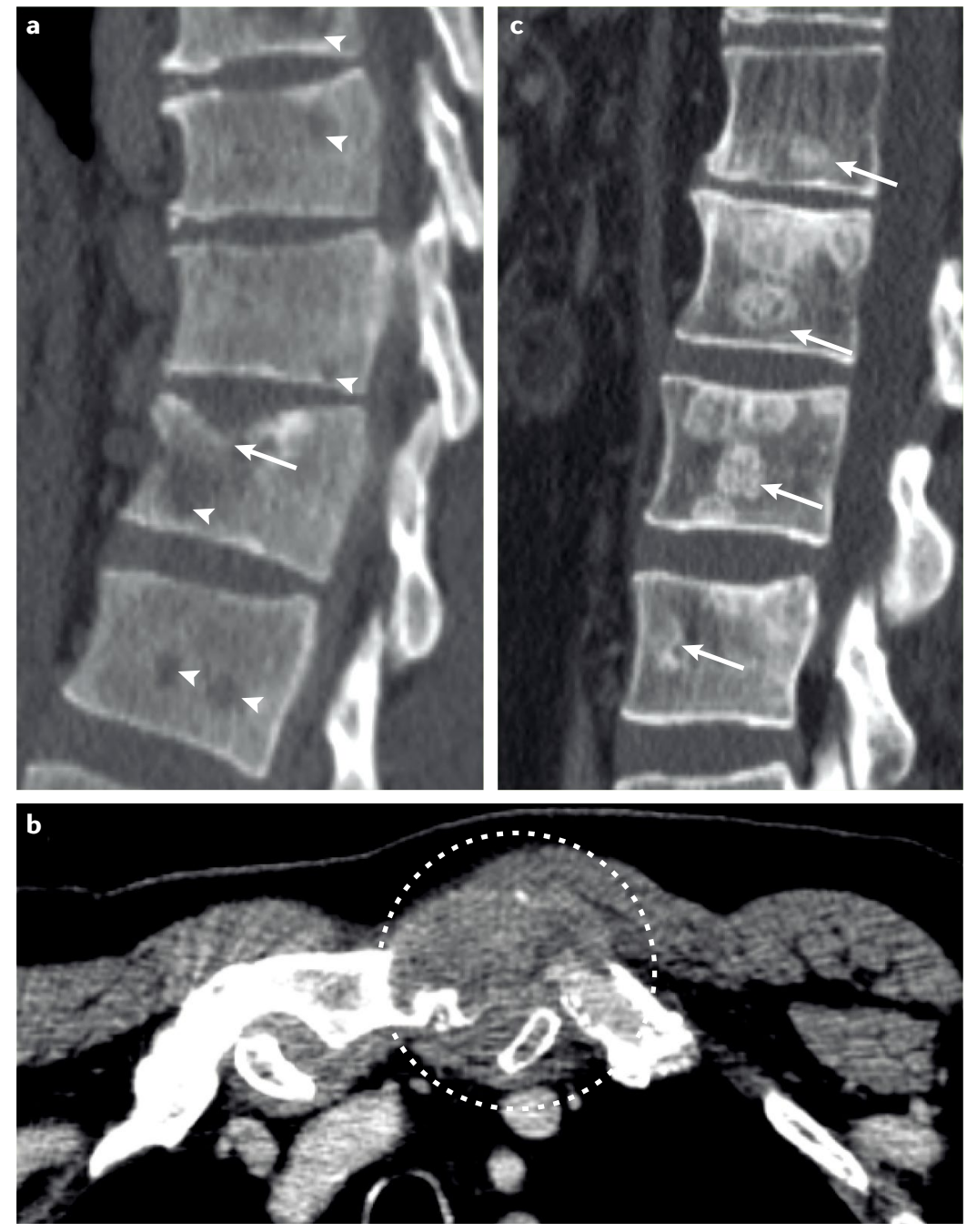

Fig. 1 | Radiographic pattern of RCC bone metastases. Bone metastases from renal cell carcinoma (RCC) can present in different patterns. a | Osteolytic bone metastases (arrowheads) that present with a symptomatic pathological fracture of the vertebral body (arrow) can be seen. $\mathbf{b}$ |Osteolytic bone metastases that present with an extraosseous soft-tissue portion in proximity to the sternoclavicular joint (dashed circle) can be seen. c| Bone metastases that result in bone formation (osteoblastic lesions) are rare (arrows).

considered in clinical decision-making. In the presence and/or persistence of clinical symptoms suggestive of bone disease, adequate imaging should be initiated.

\section{Imaging techniques in bone metastases}

Technetium-99 m $\left({ }^{99 \mathrm{~m}} \mathrm{Tc}\right)$-diphosphonate bone scintigraphy, which provides assessment of the whole skeleton, and conventional radiography are widely used for the assessment of bone metastases ${ }^{2}$ (FIG. 2). In most instances, only loss of bone mineral content $\geq 50 \%$ can be detected on radiographs, which limits their utility for detection of RCC metastases to the bone ${ }^{2,27}$. The osteolytic nature of RCC bone metastases decreases sensitivity of bone scans to $\leq 50 \%$, as bone scans depict only the osteoblastic reaction of bone to metastatic tissue, which is often absent in RCC lesions ${ }^{28}$. The deposition of bone-seeking radiopharmaceuticals occurs through physicochemical adsorption (chemisorption) to the hydroxyapatite structure of bone tissue. Purely osteolytic lesions in which bone structure is displaced by tumour cells cannot be depicted by these radiopharmaceuticals; thus, false-negative findings are common for osteolytic lesions.

$\mathrm{CT}$ is an important tool for the assessment of bone stability and structure ${ }^{27}$ (FIG. 3). Given the pattern of metastatic spread to the proximal axial skeleton, which is covered by CT of the chest, abdomen, and pelvis, most lesions that cause substantial bone loss are captured by CT; hence, follow-up monitoring can be based on routine CT imaging that includes the proximal extremities and sagittal reformations of the spine using bone windowing and a bone-specific reconstruction technique.

The true value of PET-CT with ${ }^{18} \mathrm{~F}$-sodium fluoride $\left({ }^{18} \mathrm{~F}-\mathrm{NaF}\right)$ or ${ }^{18} \mathrm{~F}$-fluorodeoxyglucose $\left({ }^{18} \mathrm{~F}-\mathrm{FDG}\right)$ in staging RCC remains to be determined. ${ }^{18} \mathrm{~F}-\mathrm{NaF}-\mathrm{PET}-\mathrm{CT}$ seems to have a higher sensitivity and accuracy than bone scan or CT in the detection of RCC bone metastases, but data are limited owing to small patient cohorts and a low number of comparative studies ${ }^{29} .{ }^{18} \mathrm{~F}$-FDG-PET without CT has demonstrated high specificity but limited sensitivity for detection of distant RCC metastases in older studies before the introduction of hybrid PET-CT, providing an overall specificity and sensitivity of $100 \%$ and $63.6 \%$, respectively ${ }^{30}$. Hybrid ${ }^{18} \mathrm{~F}$-FDG-PET-CT combines the advantages of both PET and CT and has shown high sensitivity for the detection of disease recurrence or metastasis in the post-operative surveillance of patients with advanced RCC (89.5\% sensitivity and $83.3 \%$ specificity $)^{31} \cdot{ }^{18} \mathrm{~F}-\mathrm{NaF}-\mathrm{PET}-\mathrm{CT}$ has demonstrated even higher sensitivity, albeit in small patient cohorts ${ }^{29}$. However, PET-CT is not routinely used, owing to high associated costs and availability. This technique can be used as an adjunct when conventional imaging is not conclusive, as early diagnosis of metastatic disease can drastically alter the therapeutic management.

According to the literature, MRI has $>93 \%$ sensitivity and specificity for the detection of skeletal metastases ${ }^{2,28}$ (FIG. 3). MRI is not routinely used for patient follow-up monitoring, owing to high associated costs and limited availability. In patients with seemingly solitary or oligometastatic spread to the bone, whole-body MRI should be performed before extensive surgical resections to ensure that the patient truly has a limited number of bone lesions amenable to surgical management.

\section{Contrast agents and renal impairment}

A systematic review and meta-analysis assessed the risk of acute kidney injury (AKI) from intravenous contrast medium in patients undergoing $\mathrm{CT}$ imaging with and without intravenous contrast agent for various indications, including metastatic RCC ${ }^{32}$. The risks of AKI, death, and dialysis were similar for both groups (relative risk (RR) 0.79, 95\% CI 0.62-1.02; RR 0.95, 95\% CI 0.55-1.67; and RR 0.88 , 95\% CI $0.23-3.43$, respectively). This pattern was observed regardless of contrast medium type or whether patients had renal insufficiency ${ }^{32}$, indicating that patients with RCC do not have an increased risk of AKI from intravenous contrast medium. Individual factors other than the use of contrast medium are more likely to contribute to the development of AKI. In detail, patients at low risk (serum creatinine level $(\mathrm{SCr}) \leq 1.5 \mathrm{mg} / \mathrm{dl}$ ) and intermediate risk (SCr 1.6-2.0 mg/dl) can be safely 
scanned with intravenous contrast medium, as they do not have a substantial risk of AKI. Generally, CT and MRI scans should be acquired with intravenous contrast medium unless patients have substantial impairment of renal function $(\mathrm{SCr}>2.0 \mathrm{mg} / \mathrm{dl})$.

\section{Summary of evidence}

- Bone scintigraphy has low sensitivity to detect bone metastases (LoE: 3 ).

- CT imaging is a powerful tool to assess bone structure for detection of bone metastases, with a higher sensitivity than bone scintigraphy (LoE: 4).

- MRI has very high sensitivity and specificity to detect bone metastases (LoE: 4).

- PET has high specificity, and its sensitivity depends on the applied radiotracer (LoE: 3 ).

- Individual parameters rather than use of contrast medium are associated with AKI (LoE: 4).

\section{Panel's position and recommendations}

- CT of the chest, abdomen, and pelvis, including the proximal extremities and a sagittal reconstruction of the spine using a sharp bone reconstruction kernel, is standard for diagnosis and follow-up monitoring. Biphasic contrast agents are required to characterize visceral lesions.

- In asymptomatic patients, we do not recommend specific screening for bone metastases apart from routine tumour staging by CT of the thorax, abdomen, and pelvis.

- Bone scintigraphy and 18F-FDG-PET-CT should not be routinely used to screen for bone metastases in patients with RCC.
- Conventional radiography should be considered as an initial diagnostic procedure only in patients with symptomatic bone metastases.

- MRI should be used as an extended diagnostic procedure before local treatment in suspected skeletaloligometastatic disease, as this technique has very high sensitivity in the detection of bone metastases, and its sensitivity exceeds that of bone scintigraphy.

- MRI is the preferred imaging modality to assess the extent of epidural disease in spinal metastases.

- PET can be used as an adjunct procedure when conventional imaging is not conclusive.

- We recommend biopsy for nonresectable bone metastases in the absence of prior pathological diagnosis of metastatic disease.

\section{Outstanding issues (unmet patient needs)}

- The optimal screening method for patients with a solitary bone lesion still needs to be determined.

- The availability of whole-body MRI needs to be improved, as this technique is currently the best bone screening method.

- The comparative performance of whole-body MRI and PET for detection of bone metastases needs to be determined.

- A more precise surveillance algorithm for monitoring patients with bone metastases from RCC is needed.

\section{Local therapies for RCC bone metastases}

Palliative treatment for patients with multiple bone metastases can include surgery (including minimally invasive methods, such as osteoplasty), radiotherapy, and pharmacological (including analgesic) therapy ${ }^{9,33,34}$.
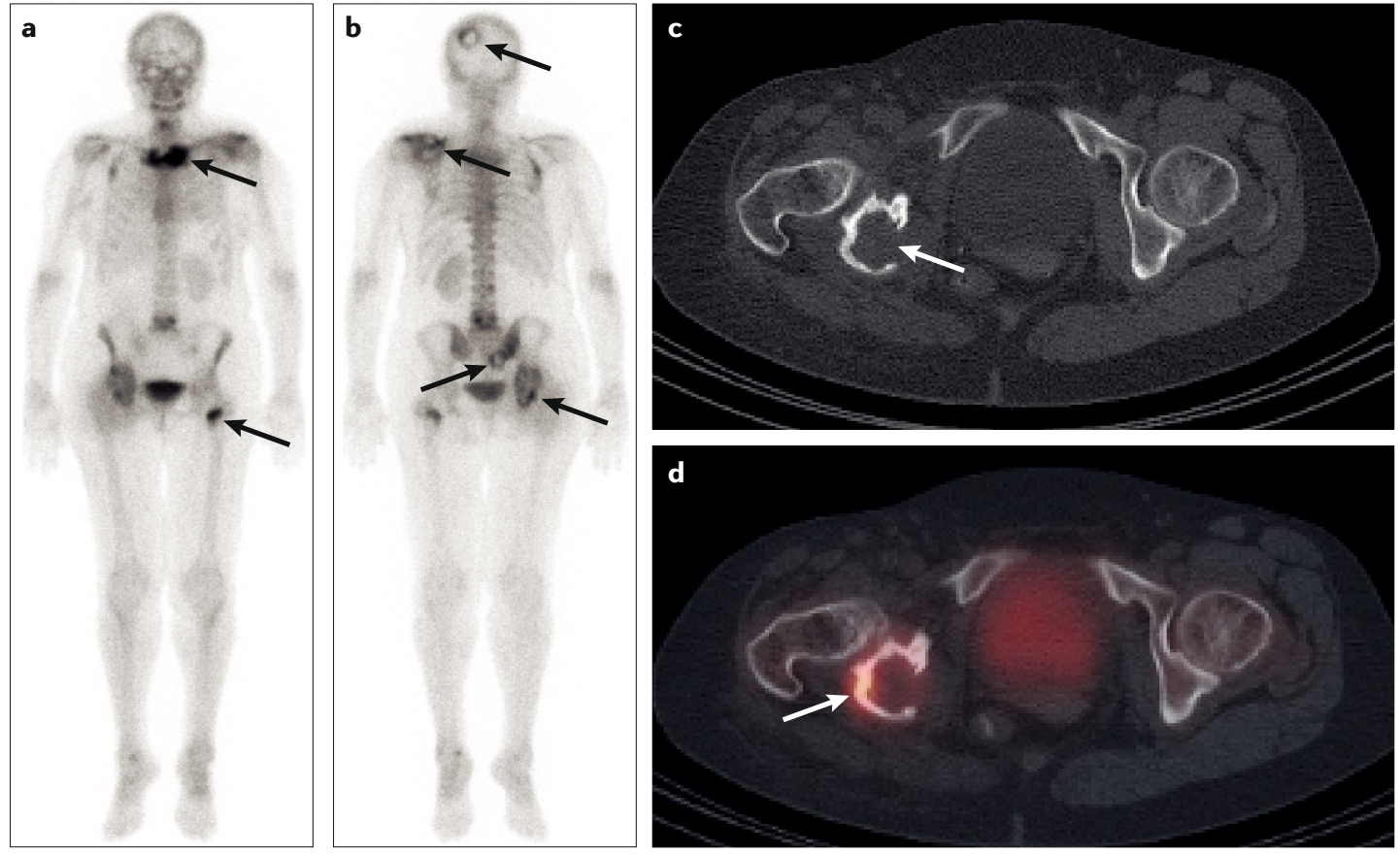

Fig. 2 | Radionuclide pattern of bone metastases from RCC. Multiple osseous bone metastases (arrows) detected by technetium-99 m ( ${ }^{99 \mathrm{~m}} \mathrm{Tc}$ )-phosphonate bone scintigraphy in anterior (part a) and posterior (part b) views. Transversal CT (part c) depicts osteolysis of the posterior right acetabulum (arrow), which shows only partially activated bone metabolism (arrow) on single-photon emission CT (SPECT)-CT (part d). RCC, renal cell carcinoma. 

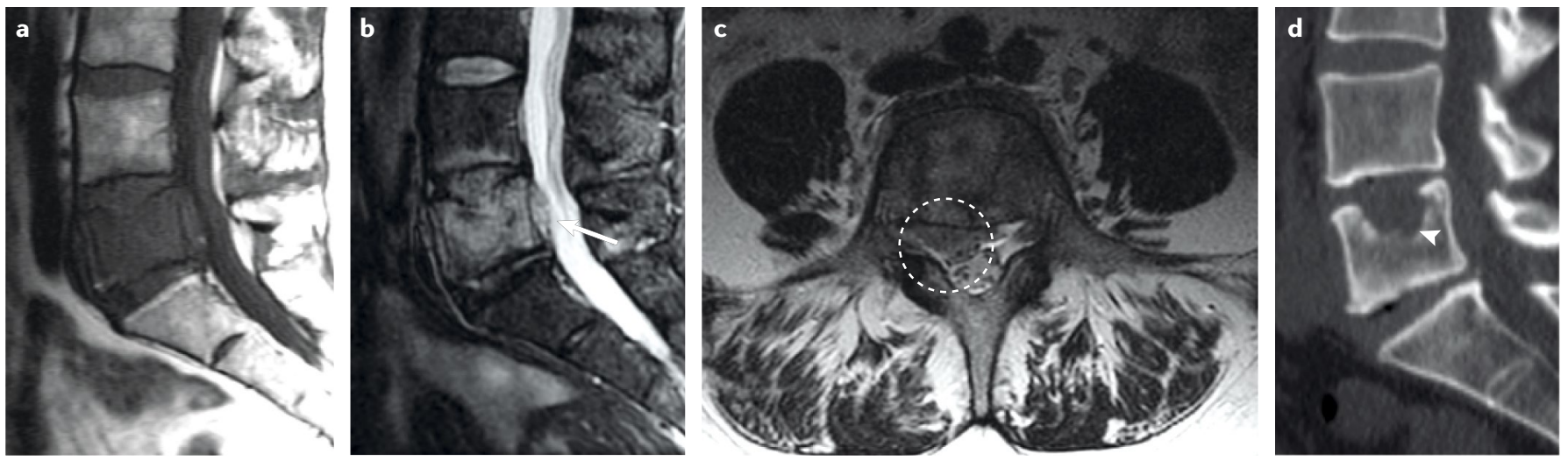

Fig. 3 | Imaging techniques for RCC bone metastases. Bone metastases of the lumbar spine are detected by MRI or CT. T1-weighted sagittal (part a), T2-weighted sagittal (part b) and T2-weighted axial (part c) MRIs show the destruction of the fifth lumbar vertebra. MRI offers benefits for the assessment of the spinal canal and its possible involvement (arrow and dashed circle). By contrast, CT imaging (part d) has the advantage of displaying the structure of the mineral bone and enables assessment of its stability in the case of osteolysis (arrowhead). RCC, renal cell carcinoma.

Solitary or oligometastatic disease should be treated with curative intent, preferably with wide resection margins.

\section{Surgery}

Indications for surgical intervention in patients with metastatic RCC to the bone are intractable pain, presence of or impending pathological fracture, spinal instability, spinal cord compression, or curative intention ${ }^{2,9,12}$. Treatment goals are improvement of prognosis, local tumour control, pain relief, and preservation or reconstitution of function. Surgical procedures include resections with or without reconstruction, internal fixation, and neural decompression ${ }^{2}$. The primary tumour and the metastasis can be resected during the same operation or at different times ${ }^{12}$.

Surgical resection of solitary or oligometastatic lesions can improve the prognosis of patients with bone metastases, supporting a multidisciplinary team approach for treatment planning in these patients ${ }^{11,24,35-37}$. In patients with a favourable or intermediate prognosis, tumour-free margins were associated with favourable survival and local tumour control; having a wide surgical margin compared with an intralesional margin improved 5-year overall survival significantly from $11 \%$ to $31 \%(P=0.028)^{24}$. Thus, wide resection of lesions should be favoured. The effect on survival also applies to patients with a limited amount of resectable osseous and visceral metastases. If all metastatic lesions can be resected, 5-year overall survival increases from $<10 \%$ to $>40 \%{ }^{24}$. Poor prognosis is associated with multiple nonresectable skeletal metastases, concomitant visceral metastases, and local recurrence ${ }^{38}$. Nevertheless, these factors should not exclude patients from receiving more elaborate reconstructions, such as endoprosthetic replacement or bone transplantation for functional improvement, as survival $>1$ year can still be expected in many patients ${ }^{24,38}$. An alternative approach for patients with spinal metastases involving epidural disease can involve multimodal therapy, consisting of surgery followed by definitive spine radiosurgery ${ }^{39}$. If rapid spinal decompression is required, direct decompression surgery plus radiotherapy was superior to radiotherapy alone in a randomized trial in 101 patients (OR 6.2, 95\% CI $2.0-19.8 ; P=0.001)^{40}$.

In one study including 45 patients with a total of 56 lesions, surgery was associated with pain relief ( $91 \%$ of patients), good-to-excellent functional outcome (89\%), and local tumour control (local recurrence in $7.1 \%$ of patients) ${ }^{36}$. Randomized studies that compare different treatment modalities are lacking, but surgery is recommended if a curative resection is intended and metastases are completely resectable, according to the German guideline on RCC 9 .

\section{Summary of evidence}

- Complete tumour resection is associated with locoregional control and survival (LoE: 5).

- Long-term survival can be achieved in patients with solitary bone metastasis (LoE: 5).

- If spinal cord decompression is required, surgical resection plus radiotherapy is superior to radiotherapy alone (LoE: 2).

\section{Radiotherapy}

Radiotherapy has important functions in the palliative management of bone lesions, including pain control, relief of spinal cord compression, and support of bone remineralization $^{41}$. Historically, RCC bone metastases were considered resistant to conventional fractionated radiotherapy ${ }^{42}$. In the past 5 years, hypofractionated regimens, consisting of a single or few fractions, have been established and are considered to be effective in metastatic $\mathrm{RCC}^{43}$. Stereotactic body radiation therapy (SBRT) delivers high doses confined to the tumour ${ }^{43-45}$ and has been reported to be feasible in patients with oligometastatic disease (local control rate $>90 \%)^{42,45-47}$. In animal models, single-dose SBRT has been associated with vascular damage ${ }^{42,43}$, suggesting synergistic effects with targeted agents in $\mathrm{RCC}^{45}$. An optimal schedule for combined treatment in humans has not yet been determined ${ }^{48}$. Phase I clinical trials have tested sunitinib or pazopanib in combination with radiotherapy in patients with RCC or central nervous system (CNS) malignancies ${ }^{49,50}$. In patients with metastatic RCC, the recommended dose for SBRT in 
combination with $800 \mathrm{mg}$ pazopanib per day was $36 \mathrm{~Gy}$ in 3 fractions ${ }^{49}$. Another phase I trial tested daily $37.5 \mathrm{mg}$ sunitinib in combination with various radiotherapy doses and fractions for different CNS malignancies ${ }^{50}$. Keeping in mind the variety in patients and radiotherapy regimens, this study reported acceptable toxicities, supporting the combined use of radiotherapy and sunitinib.

Data for SBRT for metastatic RCC mainly come from small series using different doses and schedules. Patients with various metastatic sites and locations of the primary tumour have been treated with SBRT. SBRT resulted in complete regression of irradiated lesions in $30 \%$ of patients and tumour shrinkage or stabilization in an additional $60 \%$ of patients, indicating high local control rates in $90-98 \%$ of patients as well as pain control; treatment related adverse events occurred in 39.7\% of patient $s^{51}$. A randomized trial in patients with bone metastases that included 41 patients with RCC showed that the use of $8 \mathrm{~Gy}$ in a single fraction was not inferior to and was less toxic than $20 \mathrm{~Gy}$ given in multiple fractions ${ }^{52}$. $30 \mathrm{~Gy}$ in 10 fractions is a commonly used regimen for treatment of bone metastases and has also been shown to reduce pain from bone metastases in patients with $\mathrm{RCC}^{53}$. In a retrospective study, SBRT rapidly improved symptoms and resulted in more durable clinical and radiographical responses than conventionally fractionated external beam radiotherapy in patients with metastatic RCC to the bone ${ }^{42}$. No uniform dose and fractionation was used in this study, but a biologically effective dose of $\geq 80$ Gy was associated with improved clinical local control (HR 0.140, 95\% CI 0.025-0.787; $P=0.26)^{42}$. In another study, single-dose SBRT (24 Gy) compared with hypofractionated SBRT resulted in improved 3-year local progression-free survival (88\% versus $17 \% ; P<0.001)^{54}$. In this study, only one patient had a treatment-induced vertebral fracture ${ }^{54}$, but another report has reported fractures in $7.2 \%$ of patients following single-fraction $24 \mathrm{~Gy}$ SBRT, indicating a potential severe late adverse event of spinal SBRT ${ }^{55}$.

The incidence of vertebral compression fracture (VCF) was reported to be $<5 \%$ for conventional radiotherapy ${ }^{56}$, but the incidence of VCF seems to be higher for spine SBRT, which was reported to occur in 11-18\% of lesions ${ }^{45,57-61}$. Hence, salvage treatment is required in some patients. One study reported that up to $47 \%$ of lesions required salvage kyphoplasty, surgery, or both ${ }^{58,61}$. The greatest risk factors for VCF were reported to be a high dose per fraction ( $\geq 20 \mathrm{~Gy}$ ), osteolytic disease, and pre-existing VCF or spinal deformity ${ }^{58,59}$.

Overall, clinical results showed that single-session and multiple-session stereotactic spinal radiosurgeries are noninvasive, safe, and effective treatments for patients with spinal lesions. A single fraction provides more rapid symptom and quality of life improvement but is associated with a higher re-treatment rate in long-term survivors $(1 \% \text { versus } 13 \%, P<0.001)^{41,62}$.

\section{Thermal ablation}

Radiofrequency ablation is a percutaneous method for symptom relief and local control of bone metastases ${ }^{63,64}$, which can be combined with vertebroplasty to stabilize vertebrae ${ }^{65,66}$. Radiofrequency ablation can destroy the metastatic tumour tissue but leaves a cavity in the bone, which reduces its mechanical stability ${ }^{66}$. Ex vivo testing in a human spine model showed that the combination of radiofrequency ablation and vertebroplasty resulted in improved stability and axial loading of the vertebrae compared with ablation alone ${ }^{66}$, highlighting the importance of multimodal concepts in the treatment of bone metastases in metastatic RCC. Percutaneous image-guided ablation has been advocated to relieve pain, reduce tumour burden, and provide mechanical stabilization of the bone ${ }^{67}$. Initial results suggest that radiofrequency ablation in patients with painful bone metastases is safe and reduces pain levels (efficacy in 23 of 33 patients $(69.7 \%))^{68}$. The analgesic effect is reported to reach significance as early as day 7 after radiofrequency ablation, highlighting the early onset of clinical efficacy of this technique ${ }^{69}$. The applicability of radiofrequency ablation is limited by the cooling effect of local blood flow (heat sink effect) and the high electrical impedance of tissues. A study from 2018 compared the heat sink effect for radiofrequency and microwave ablation in the liver. Microwave ablation maintained a consistent surface temperature irrespective of the proximity of vessels, whereas a temperature drop by one-third near vessels was noted for radiofrequency ablation, indicating the limitations of this technique ${ }^{70}$.

The efficacy of cryoablation for the treatment of RCC was first described in the early $1970 \mathrm{~s}^{71}$. Cryoablation is currently used to treat either RCC primary tumours or metastases, including lesions of the bone, and is an alternative to radiofrequency ablation ${ }^{72,73}$. In a retrospective series, cryoablation of bone metastases from RCC resulted in high local tumour control in $81 \%$ of 50 lesions $^{74}$. Preliminary data indicate similar levels of pain relief ( $68 \%$ and $64 \%$ of patients for cryoablation and radiofrequency ablation, respectively) and a significant increase in quality of life $(P<0.001)$ for both approaches $^{75}$. Future work should investigate differences between these techniques to support appropriate use of the most adequate technique in the individual patient.

\section{Summary of evidence}

- Tyrosine kinase inhibitors (TKIs) can be given concomitantly with radiotherapy (LoE: 3 ).

- Hypofractionated radiotherapy is superior to standard fractionated radiotherapy (LoE: 4).

- SBRT has promising clinical effectiveness (LoE: 3 ).

- Radiotherapy should be performed after decompressing surgery for metastases of the spine (LoE: 2).

- Radiofrequency ablation exerts local tumour control and reduction of symptoms (LoE: 5).

- Cryoablation might be used to control the primary tumour or bone metastases (LoE: 5).

\section{Panel's position and recommendations}

- Adequate pain therapy is the mainstay in the management of patients with symptomatic bone metastases.

- Local therapies are the preferred choice of treatment to achieve tumour control.

- We recommend giving priority to local treatment of bone metastases in the case of instability, fracture, 
pain, or neurological impairment or as an individual decision based on a patient's risk profile.

- Wide resection with curative intent is the primary approach to solitary or oligometastatic bone metastasis. Even in patients with further metastatic disease, local wide resection might substantially and durably improve quality of life; however, mutilating surgery should be avoided.

- Additive radiotherapy after resection of bone metastases resulting in negative margins (locoregional R0) is not indicated.

- Medical treatment after resection resulting in negative margins (locoregional R0) is not indicated; however, in the presence of residual disease or additional metastases and lack of local therapeutic options, medical treatment should be offered.

- Radiotherapy should be given as a single high-dose (radiosurgery) or hypofractionated stereotactic regimen.

- We do not recommend conventionally fractionated radiotherapy for the treatment of RCC.

- In patients who require both medical treatment and radiotherapy, we suggest combining both treatment modalities.

- Symptomatic bone metastases should preferably receive wide resections whenever feasible or, otherwise, intralesional resections and reconstructions or SBRT in inoperable cases.

- Radiofrequency ablation, microwave ablation, and cryoablation are treatment options in individual patients with bone metastases $<3 \mathrm{~cm}$.

- Patients with asymptomatic bone metastases should receive active surveillance, pre-emptive local therapy (in high-risk patients), or systemic therapy, if appropriate.

\section{Medical therapy \\ Targeted therapies}

TKIs and anti-vascular endothelial growth factor (VEGF) antibodies are widely used as first-line and second-line treatments of advanced RCC ${ }^{12}$. Direct evidence on the effects of targeted agents on bone metastases is currently limited to a few studies, which suggest that TKIs can extend the mean time to progression of existing bone lesions and reduce formation of new bone lesions ${ }^{2,76}$.

A retrospective analysis of data from 375 patients with metastatic RCC showed that patients with bone metastases treated with the first-generation TKIs sunitinib or sorafenib had improved overall survival compared with historical controls (24 months versus 18 months; $P<0.01)^{77}$. This finding is supported by another retrospective study, which compared the effect of IFNa, sunitinib, and sorafenib on the occurrence and progression of metastatic bone lesions in 292 patients with $\mathrm{RCC}^{76}$. Sunitinib decreased the formation $(P=0.034)$ and time to new bone lesions $(P=0.047)$ compared with sorafenib. Preclinical evidence suggests that sunitinib inhibits osteoclast activity, corroborating this clinical observation ${ }^{78}$.

Treatment with cabozantinib, a third-generation TKI, resulted in improved survival in two clinical studies, indicating the important role of this class of agents in the treatment of these patients ${ }^{79}$. The subgroup analyses of patients with bone metastases in the phase II first-line study comparing cabozantinib and sunitinib and the second-line phase III study comparing cabozantinib and everolimus found improved progression-free survival with cabozantinib treatment (HR 0.54, 95\% CI 0.31-0.95 and HR 0.33, $95 \%$ CI $0.21-0.51$, respectively ${ }^{79}$. In second-line use, cabozantinib was also associated with a better overall survival (HR 0.54, 95\% CI 0.34-0.84). Results of an in vitro study suggest that these effects are mediated by direct inhibition of osteoclast activity and modulation of the bone microenvironment through alteration of the receptor activator of nuclear factor- $\kappa \mathrm{B}$ ligand (RANKL; also known as TNFSF11):osteoprotegerin ratio in osteoblasts ${ }^{80}$. In addition, treatment with nivolumab, an antibody against programmed cell death protein 1 (PD1), resulted in improved survival compared with everolimus in patients with metastatic RCC, which was maintained in the subgroup of patients with bone metastases ${ }^{81}$.

\section{Bisphosphonates and antibodies}

Bone-targeting agents such as bisphosphonates and denosumab have been shown to reduce SREs and the worsening of pain associated with bone metastases and to improve the control of hypercalcaemia in patients with different advanced malignancies, including $\mathrm{RCC}^{82,83}$. Thus, bone-targeting agents are recommended for patients with or without pain caused by bone metastases from solid tumours ${ }^{84}$. Current evidence supports the surgical and/or radiotherapeutic treatment of bone metastases in patients with RCC, but the role of systemic bone-targeted treatment is less well defined.

Bisphosphonates. Bisphosphonates are a heterogeneous group of bone-targeting agents, which are absorbed by active osteoclasts, thereby blocking their activity ${ }^{85}$. Zoledronic acid is a potent inhibitor of osteoclast activity and is commonly used for treatment of bone metastases in patients with $\mathrm{RCC}^{26}$. Data in patients with RCC and bone metastases are limited to a subgroup analysis from a pivotal phase III study $(n=74)$ and a phase II trial $(n=50)$, which were performed when targeted therapies for RCC were not yet available ${ }^{86-88}$. In these trials, zoledronic acid treatment decreased the rate of SREs to $22-37 \%$, which compared favourably with a rate of $74 \%$ SREs in the placebo control arm of the phase III study $^{86-88}$. By contrast, a pooled analysis of data from 2,794 patients with RCC mainly treated with targeted therapies did not show a correlation between bisphosphonate, including zoledronic acid, use and outcomes (progression-free survival, overall survival, or SRE incidence ${ }^{89}$. Interestingly, the rates of SREs in patients with or without bisphosphonate use were $8.6 \%$ and $5.8 \%(P=0.1785)$, respectively, possibly underscoring the value of active antitumour therapy given to patients with RCC in recent years. Furthermore, an increase in hypocalcaemia, renal insufficiency, and osteonecrosis of the jaw $(\mathrm{ONJ})$ was associated with the use of bisphosphonates $(P<0.0001)^{89}$. Adverse effects can be 
substantial. Atypical femur fractures have been reported for long-term use of bisphosphonates, including zoledronic acid ${ }^{90}$. In addition, zoledronic acid requires renal function monitoring and corresponding dose adjustments ${ }^{44}$, which is of particular relevance in patients with $\mathrm{RCC}^{2}$ and are not required for denosumab treatment. As a class effect, bisphosphonates are associated with the risk of hypocalcaemia and, therefore, require calcium and vitamin D supplementation. Overall, bisphosphonates alone are of limited value in patients with bone metastases from RCC and are often used as an adjunct to targeted therapies. While the value of bisphosphonates in combination with TKIs remains unclear, such combinations have been associated with an increase of the incidence of $\mathrm{ONJ}^{89,91}$.

Denosumab. Denosumab inhibits RANKL, thereby blocking osteoclast activity ${ }^{2,12,26,44}$. A phase III trial demonstrated noninferiority for denosumab compared with zoledronic acid in delaying time to first on-study SRE in patients with bone metastases from various primary cancers (HR 0.84, 95\% CI 0.71-0.98) ${ }^{83}$. In the subgroup of patients with solid primary tumours, denosumab was more effective in delaying or preventing SREs in patients with bone metastases (HR 0.81, 95\% CI 0.68-0.96) and also prevented pain progression (HR 0.83, 95\% CI 0.71-0.97) compared with zoledronic acid $^{92}$. In a meta-analysis of data from 3 pivotal trials in $>5,700$ patients, denosumab improved time to first SRE by a median of 8.21 months and reduced the risk of a first SRE by $17 \%$ compared with zoledronic acid ${ }^{93}$. The pivotal phase III trial included patients with various cancers and bone metastases, but no specific subgroup analyses for those with RCC was reported ${ }^{83}$, precluding a recommendation of denosumab in patients with metastatic RCC.

Osteonecrosis of the jaw. ONJ is a rare (1.3-1.8\%) but potentially serious event in patients with cancer who receive bisphosphonates or denosumab ${ }^{2,44,94}$. Some evidence exists that the combination of bisphosphonates and antiangiogenic therapies is more frequently associated with ONJ than bisphosphonates alone ${ }^{89,91}$. Published consensus recommendations $\mathrm{s}^{95}$ and evidencebased guidelines for the prevention and management of ONJ include regular dental examinations before and during treatment, elimination or stabilization of oral disease before initiation of these agents, and maintenance of good oral hygiene?.

\section{Combination therapy}

Zoledronic acid treatment has been associated with response to radiotherapy in six of ten patients with bone metastases from $\mathrm{RCC}^{96}$ and with a favourable SRE-free survival and pain response compared with radiotherapy alone ${ }^{97}$, possibly mediated by a radiotherapy-sensitizing effect of zoledronic acid on RCC cells ${ }^{98}$. Simultaneous antiangiogenic therapy and stereotactic radiosurgery in patients with spinal or cerebral metastases from RCC was associated with high local tumour control (98\% of patients) after a 15 -month follow-up period without an increase in adverse events, indicating that combination therapy can be offered to select patients ${ }^{99}$.

\section{Summary of evidence}

- TKIs have clinical activity in metastatic RCC with bone metastases (LoE: 2).

- Cabozantinib treatment resulted in superior outcomes compared with everolimus or sunitinib in patients with metastatic RCC and bone metastases (LoE: 2).

- Bisphosphonates decrease SREs in patients with metastatic RCC and bone metastases (LoE: 2).

\section{Panel's position and recommendations}

- Pharmacological treatment for bone metastases is given with palliative intent only.

- Targeted therapies should be used to treat bone metastases that are not amenable to local therapies.

- Among available targeted therapies, cabozantinib should be used preferentially in patients with multiple bone metastases.

- Bone-targeted agents should be used to control tumour-associated hypercalcaemia.

- Whether bisphosphonates or denosumab treatment in addition to targeted therapy improves clinical outcomes is uncertain.

- The combination of osteoprotective therapy and targeted agents increases the risk of adverse events, such as ONJ.

- No reliable evidence of a long-term osteoprotective treatment exists; hence, the duration of therapy should be chosen on the basis of disease stage, individual risk, and symptoms.

- If bone-directed symptoms recur during pauses of anticancer drug treatment, an alternative dose regimen should be considered (continuous therapy or shortening of the drug-free interval).

- Early, immediate, and individual pain therapy should be offered to symptomatic patients and requires continuous monitoring. Local therapy should be considered again if symptoms worsen.

\section{Outstanding issues (unmet patient needs)}

- The benefit and duration of osteoprotective therapy in patients with RCC and bone metastases who receive targeted therapies remain to be defined.

- A clinical need exists in the palliative setting to improve systemic therapies to control bone metastases effectively in terms of response and symptoms.

\section{Other therapies \\ Radionuclide therapy}

Radionuclide therapy of bone metastases with boneseeking radiopharmaceuticals, such as samarium-153ethylene diamine tetra(methylene phosphonic acid) $\left({ }^{153} \mathrm{Sm} \text {-EDTMP }\right)^{100-103}$, is not indicated outside of clinical studies owing to the predominantly osteolytic nature of bone metastases in RCC. The deposition of bone-seeking radiopharmaceuticals occurs at the mineralization front of bone (osteoid) but not near osteoclasts and not within the osteolytic metastatic lesion itself that has displaced the normal hydroxyapatite structure of bone tissue. 


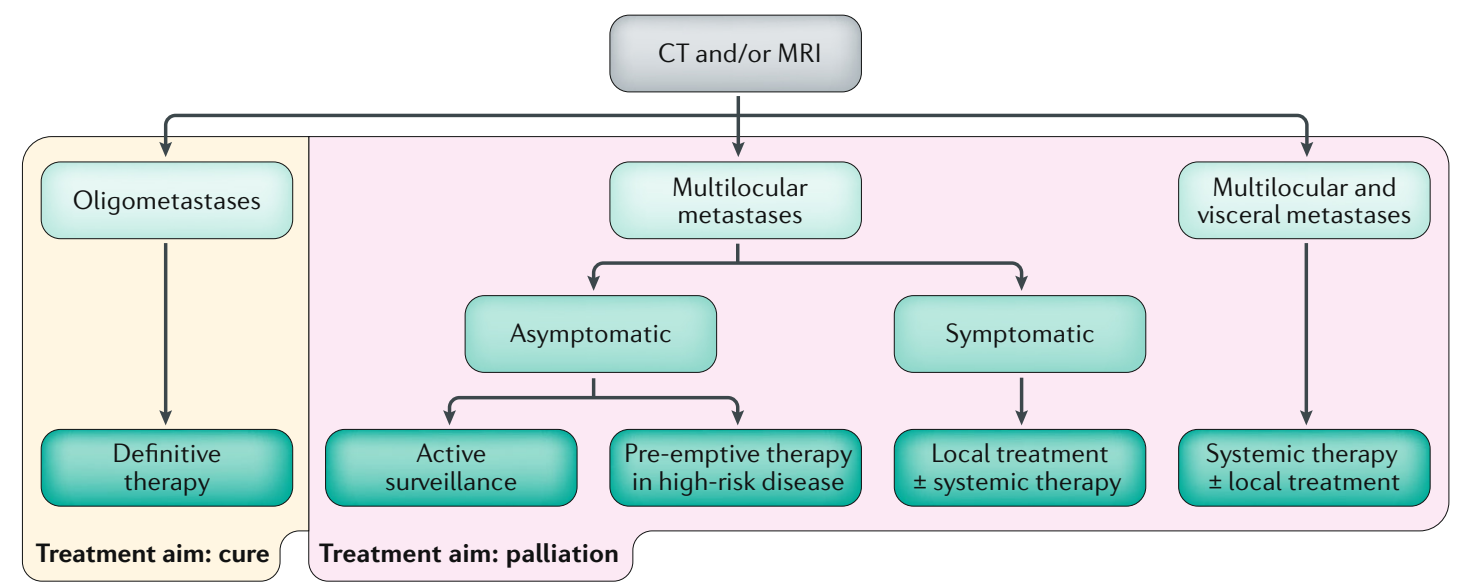

Fig. 4 | Proposed treatment algorithm for patients with RCC and bone metastasis. The multidisciplinary expert panel proposes an algorithm for the management of patients with metastatic bone disease arising from renal cell carcinoma (RCC). The extent and location of metastasis should be assessed using CT and/or MRI. In patients with oligometastatic bone disease, disease cure is the aim of treatment and surgery is the preferred treatment option. However, other definitive therapy options might also be applicable, and the approach should be individualized to the needs of the patient. In other patients, management aims to palliate symptoms. In patients with multilocular bone metastases, treatment choice depends on the presence of symptoms. Asymptomatic patients can either undergo active surveillance or pre-emptive therapy in cases of high-risk disease. Symptomatic patients with multilocular disease should be assessed for local treatment first. Instability, fracture, pain, neurological impairment, and individual decision should be used for proper clinical judgement of local therapies. Surgery with or without radiotherapy remains the mainstay of treatment in symptomatic disease, but the approach should be individualized. Medical treatment can be given in the presence of residual disease or additional metastases but is not recommended as an adjunct after complete resection or definite locoregional treatment. In patients with multilocular bone and visceral metastases, systemic therapy is the mainstay of treatment, which can be amended by local treatments depending on pain, fracture, instability, or neurological symptoms. Bone-targeted agents can be used in patients with multilocular bone disease as an adjunct to locoregional or systemic therapies, which are the cornerstones to treat bone disease from RCC. An individual decision should be made for the duration of bone-targeted therapies, as specific adverse events of the bone can occur with long-term use. Stage of disease, individual risk of local complications, and patient symptoms should be used for clinical decision-making.

\section{Therapeutic embolization}

Transarterial embolization is generally used in primary or metastatic bone tumours ${ }^{63}$ to reduce operative haemorrhagic risks or to simplify or enable more definitive surgery or in the context of palliation ${ }^{104}$. Clinical response to embolization has been reported in patients with $\mathrm{RCC}^{105-107}$. A small series including 21 patients and 39 metastatic bone lesions reported a clinical response in 36 lesions, with a median response duration of 5.5 months ${ }^{105}$, highlighting a role of embolization in select patients.

\section{Panel's position and recommendations}

- Radionuclide therapy should not be used outside of clinical studies owing to limited established data.

- Transarterial embolization should be considered before resection of bone metastases.

\section{Conclusions}

On the basis of the available evidence and expert opinion, we propose an algorithm for the clinical management of patients with RCC and bone metastasis (FIC. 4). Multidisciplinary care is essential for maximizing patient benefit, and adequate pain management should be ensured in all patients. Surgery is a curative approach in select patients. If indicated, surgery should be performed before commencing pharmacological treatment. Considerable technological advances in radiotherapy, such as SBRT and stereotactic radiosurgery, have enabled the delivery of high doses with an accuracy within millimetres, which broadens our perception of the use of radiotherapy beyond the scope of symptom control. We propose that medical drug treatment should not be discontinued when radiotherapy is given. Bone metastases respond well to systemic therapy, and an added value has been described for systemic targeted therapy. However, the most active agent for the treatment of bone metastases still needs to be defined.

Data on the use of osteoprotective treatment in patients with RCC remain unsatisfying. Targeted therapies boosted the effectiveness of pharmacological treatment, including responses in patients with bone metastases. Whether osteoprotective measures are necessary in the context of targeted therapies remains unclear, as the largest retrospective series does not support this notion. However, the combination of osteoprotective and targeted therapy comes at the expense of additional and sometimes debilitating toxicities. Personalized therapy for patients with RCC and bone metastases remains an important topic and offers several clinical questions for future research. The main goal is to incorporate patients' needs into the management strategy for bone metastases from RCC.

Published online 14 June 2018 
1. Adiga, G. U. et al. Characterization of bone metastases in patients with renal cell cancer. BJU Int. 93 1237-1240 (2004).

2. Wood, S. L. \& Brown, J. E. Skeletal metastasis in renal cell carcinoma: current and future management options. Cancer Treat. Rev. 38, 284-291 (2012).

3. Woodward, E. et al. Skeletal complications and survival in renal cancer patients with bone metastases. Bone 48, 160-166 (2011)

4. Weber, K., Doucet, M. \& Kominsky, S. Renal cell carcinoma bone metastasis - elucidating the molecular targets. Cancer Metastasis Rev. 26 691-704 (2007).

5. Santoni, M. et al. Bone metastases in patients with metastatic renal cell carcinoma: are they always associated with poor prognosis? J. Exp. Clin. Cancer Res. 34, 10 (2015).

6. Zekri, J. et al. The skeletal metastatic complications of renal cell carcinoma. Int. J. Oncol. 19, 379-382 (2001). Patrick, D. L. et al. Pain outcomes in patients with bone metastases from advanced cancer: assessment and management with bone-targeting agents. Support. Care Cancer 23, 1157-1168 (2015).

8. Junker, K. et al. Genetic profile of bone metastases in renal cell carcinoma. Eur. Urol. 45, 320-324 (2004).

9. Leitlinienprogramm Onkologie. S3 - Leitlinie, diagnostik, therapie und nachsorge des nierenzellkarzinom. AWMF http://www.awmf.org/ uploads/tx_szleitlinien/043-017OL-k_S3 Nierenzellkarzinom_2017-03.pdf (2017)

10. Escudier, B. et al. Renal cell carcinoma: ESMO Clinical Practice Guidelines for diagnosis, treatment and follow-up. Ann. Oncol. 25 (Suppl. 3), iii49-56 (2014).

11. Mottet, N. et al. EAU - ESTRO - ESUR - SIOG Guidelines on Prostate Cancer. EAU http://uroweb.org/ guideline/prostate-cancer (2018).

12. Motzer, R. et al. Kidney cancer, version 2.2017, NCCN clinical practice guidelines in oncology. J. Nat/ Compr. Canc. Netw. 15, 804-834 (2017)

13. Dabestani, S. et al. Local treatments for metastases of renal cell carcinoma: a systematic review. Lancet Oncol. 15, e549-561 (2014).

14. Bianchi, M. et al. Distribution of metastatic sites in renal cell carcinoma: a population-based analysis. Ann. Oncol. 23, 973-980 (2012).

15. Santini, D. et al. Natural history of malignant bone disease in renal cancer: final results of an Italian bone metastasis survey. PLOS One 8, e83026 (2013).

16. Aoki, J. et al. Osteoclast-mediated osteolysis in bone metastasis from renal cell carcinoma. Cancer 62 , 98-104 (1988).

17. Salapura, V. et al. Osteoblastic bone metastases from renal cell carcinoma. Radiol. Oncol. 48, 243-246 (2014).

18. Forbes, G. S., McLeod, R. A. \& Hattery, R. R. Radiographic manifestations of bone metastases from renal carcinoma. AJR Am. J. Roentgenol. 129, 61-66 (1977).

19. Yuasa, T. et al. Treatment outcome and prognostic factors in renal cell cancer patients with bone metastasis. Clin. Exp. Metastasis 28, 405-411 (2011)

20. Toyoda, Y. et al. Survival and prognostic classification of patients with metastatic renal cell carcinoma of bone. Eur. Urol. 52, 163-168 (2007).

21. Ivanyi, P. et al. Does the onset of bone metastasis in sunitinib-treated renal cell carcinoma patients impact the overall survival? World J. Urol. 34, 909-915 (2016).

22. Ruatta, F. et al. Prognosis of renal cell carcinoma with bone metastases: experience in 300 consecutive patients [abstract]. J. Clin. Oncol. 35, 463 (2017).

23. Lin, P. P. et al. Patient survival after surgery for osseous metastases from renal cell carcinoma. J. Bone Joint Surg. Am. 89, 1794-1801 (2007).

24. Fottner, A. et al. Bone metastases from renal cell carcinoma: patient survival after surgical treatment. BMC Musculoskelet. Disord. 11, 145 (2010).

25. Kume, H. et al. Prognostic factors for renal cell carcinoma with bone metastasis: who are the long-term survivors? J. Urol. 185, 1611-1614 (2011).

26. Chen, S. C. \& Kuo, P. L. Bone metastasis from renal cell carcinoma. Int. J. Mol. Sci. 17, E987 (2016).

27. Rybak, L. D. \& Rosenthal, D. I. Radiological imaging for the diagnosis of bone metastases. Q. J. Nucl. Med. 45, 53-64 (2001).

28. Sohaib, S. A. et al. Comparison of whole-body MRI and bone scintigraphy in the detection of bone metastases in renal cancer. Br. J. Radiol. 82, 632-639 (2009).

29. Gerety, E. L. et al. Prospective study evaluating the relative sensitivity of $18 \mathrm{~F}-\mathrm{NaF} \mathrm{PET} / \mathrm{CT}$ for detecting skeletal metastases from renal cell carcinoma in comparison to multidetector CT and 99mTc-MDP bone scintigraphy, using an adaptive trial design. Ann. Oncol. 26, 2113-2118 (2015)

30. Majhail, N. S. et al. F-18 fluorodeoxyglucose positron emission tomography in the evaluation of distant metastases from renal cell carcinoma. J. Clin. Oncol. 21, 3995-4000 (2003)

31. Park, J. W., Jo, M. K. \& Lee, H. M. Significance of 18F-fluorodeoxyglucose positron-emission tomography/computed tomography for the postoperative surveillance of advanced renal cell carcinoma. BJU Int. 103, 615-619 (2009).

32. McDonald, J. S. et al. Frequency of acute kidney injury following intravenous contrast medium administration a systematic review and meta-analysis. Radiology 267, 119-128 (2013).

33. Shinoto, M. et al. Percutaneous osteoplasty for hypervascular bone metastasis. Radiat. Med. 26 603-608 (2008)

34. Leung, O. C. et al. Percutaneous cementoplasty of osteolytic metastases induces immediate and long-lasting pain relief in oncological patients. Hong Kong Med. J. 19, 317-322 (2013).

35. Fuchs, B., Trousdale, R. T. \& Rock, M. G. Solitary bony metastasis from renal cell carcinoma: significance of surgical treatment. Clin. Orthop. Relat. Res. 431, 187-192 (2005).

36. Kollender, Y. et al. Metastatic renal cell carcinoma of bone: indications and technique of surgical intervention. J. Urol. 164, 1505-1508 (2000).

37. Alt, A. L. et al. Survival after complete surgical resection of multiple metastases from renal cell carcinoma Cancer 117, 2873-2882 (2011).

38. Hwang, N. et al. Massive endoprosthetic replacement for bone metastases resulting from renal cell carcinoma: factors influencing patient survival. Eur. J. Surg. Oncol. 40, 429-434 (2014).

39. Laufer, I. et al. Local disease control for spinal metastases following "separation surgery" and adjuvant hypofractionated or high-dose single-fraction stereotactic radiosurgery: outcome analysis in 186 patients. J. Neurosurg. Spine 18, 207-214 (2013)

40. Patchell, R. A. et al. Direct decompressive surgical resection in the treatment of spinal cord compression caused by metastatic cancer: a randomised trial. Lancet 366, 643-648 (2005).

41. McDonald, R. et al. Effect of radiotherapy on painful bone metastases: a secondary analysis of the $\mathrm{NCIC}$ clinical trials group symptom control trial SC.23. JAMA Oncol. 3, 953-959 (2017).

42. Amini, A. et al. Local control rates of metastatic renal cell carcinoma (RCC) to the bone using stereotactic body radiation therapy: Is RCC truly radioresistant? Pract. Radiat. Oncol. 5, e589-e596 (2015)

43. De Meerleer, G. et al. Radiotherapy for renal-cell carcinoma. Lancet Oncol. 15, e 170-e 177 (2014).

44. North, S. A. et al. Management of advanced kidney cancer: Canadian Kidney Cancer Forum consensus update. Can. Urol. Assoc. J. 9, 164-170 (2015).

45. Taunk, N. K. et al. Spine radiosurgery in the management of renal cell carcinoma metastases. J. Natl Compr. Canc. Netw. 13, 801-809 (2015).

46. Tree, A. C. et al. Stereotactic body radiotherapy for oligometastases. Lancet Oncol. 14, e28-e37 (2013).

47. Wowra, B. et al. Cyberknife radiosurgery for malignant spinal tumors: characterization of well-suited patients. 33, 2929-2934 (2008)

48. Mazeron, R. et al. Current state of knowledge regarding the use of antiangiogenic agents with radiation therapy. Cancer Treat. Rev. 37, 476-486 (2011).

49. De Wolf, K. et al. Combined high dose radiation and pazopanib in metastatic renal cell carcinoma: a phase dose escalation trial. Radiat. Oncol. 12, 157 (2017).

50. Wuthrick, E. J. et al. A phase $1 \mathrm{~b}$ trial of the combination of the antiangiogenic agent sunitinib and radiation therapy for patients with primary and metastatic central nervous system malignancies. Cancer 117, 5548-5559 (2011)

51. Wersall, P. J. et al. Extracranial stereotactic radiotherapy for primary and metastatic renal cel carcinoma. Radiother. Oncol. 77, 88-95 (2005).

52. Chow, E. et al. Single versus multiple fractions of repeat radiation for painful bone metastases: a randomised, controlled, non-inferiority trial. Lancet Oncol. 15, 164-171 (2014).

53. Lee, J. et al. A phase II trial of palliative radiotherapy for metastatic renal cell carcinoma. Cancer 104, 1894-1900 (2005).

54. Zelefsky, M. J. et al. Tumor control outcomes after hypofractionated and single-dose stereotactic imageguided intensity-modulated radiotherapy for extracrania metastases from renal cell carcinoma. Int. J. Radiat. Oncol. Biol. Phys. 82, 1744-1748 (2012).
55. Virk, M. S. et al. Frequency of symptomatic vertebral body compression fractures requiring intervention following single-fraction stereotactic radiosurgery for spinal metastases. Neurosurg. Focus 42, E8 (2017)

56. Chow, E. et al. Palliative radiotherapy trials for bone metastases: a systematic review. J. Clin. Oncol. 25, 1423-1436 (2007)

57. Rose, P. S. et al. Risk of fracture after single fraction image-guided intensity-modulated radiation therapy to spinal metastases. J. Clin. Oncol. 27, 5075-5079 (2009).

58. Cunha, M. V. et al. Vertebral compression fracture (VCF) after spine stereotactic body radiation therapy (SBRT): analysis of predictive factors. Int. J. Radiat. Oncol. Biol. Phys. 84, e343-e349 (2012).

59. Sahgal, A. et al. Vertebral compression fracture after spine stereotactic body radiotherapy: a multiinstitutional analysis with a focus on radiation dose and the spinal instability neoplastic score. J. Clin. Oncol. 31, 3426-3431 (2013).

60. Thibault, I. et al. Spine stereotactic body radiotherapy for renal cell cancer spinal metastases: analysis of outcomes and risk of vertebral compression fracture. J. Neurosurg. Spine 21, 711-718 (2014).

61. Sahgal, A. et al. Vertebral compression fracture after stereotactic body radiotherapy for spinal metastases. Lancet Oncol. 14, e310-e320 (2013).

62. Heron, D. E. et al. Single-session and multisession CyberKnife radiosurgery for spine metastasesUniversity of Pittsburgh and Georgetown University experience. J. Neurosurg. Spine 17, 11-18 (2012).

63. Mavrogenis, A. F. et al. Modern palliative treatments for metastatic bone disease: awareness of advantages, disadvantages, and guidance. Clin. J. Pain 32, 337-350 (2016)

64. Gillams, A. Tumour ablation: current role in the liver kidney, lung and bone. Cancer Imaging 8, S1-S5 (2008)

65. Lane, M. D. et al. Combination radiofrequency ablation and cementoplasty for palliative treatment of painful neoplastic bone metastasis: experience with 53 treated lesions in 36 patients. Skeletal Radiol. 40, 25-32 (2011).

66. Pezeshki, P. S. et al. Comparison of the effect of two different bone-targeted radiofrequency ablation (RFA) systems alone and in combination with percutaneous vertebroplasty (PVP) on the biomechanical stability of the metastatic spine. Eur. Spine J. 25, 3990-3996 (2016).

67. Ma, Y. et al. Percutaneous image-guided ablation in the treatment of osseous metastases from non-small cell lung cancer. Cardiovasc. Intervent. Radiol. 41, 726-733 (2018)

68. Tanigawa, N. et al. Phase I//I study of radiofrequency ablation for painful bone metastases: Japan Interventional Radiology in Oncology Study Group 0208. Cardiovasc. Intervent. Radiol. 25, 267-266 (2018).

69. Alemann, G. et al. Treatment of painful extraspinal bone metastases with percutaneous bipolar radiofrequency under local anesthesia: feasibility and efficacy in twenty-eight cases. J. Palliat. Med. 17, 947-952 (2014)

70. Primavesi, F. et al. Thermographic real-timemonitoring of surgical radiofrequency and microwave ablation in a perfused porcine liver model. Oncol. Lett. 15, 2913-2920 (2018).

71. Marcove, R. C. et al. Cryosurgery in the treatment of solitary or multiple bone metastases from renal cell carcinoma. J. Urol. 108, 540-547 (1972).

72. Rohde, D. et al. Regional thermoablation of local or metastatic renal cell carcinoma. Oncol. Rep. 10, 753-757 (2003).

73. Bang, H. J. et al. Percutaneous cryoablation of metastatic renal cell carcinoma for local tumor control: feasibility, outcomes, and estimated cost-effectiveness for palliation. J. Vasc. Interv. Radiol. 23, 770-777 (2012).

74. Gardner, C. S. et al. Cryoablation of bone metastases from renal cell carcinoma for local tumor control. J. Bone Joint Surg. Am. 99, 1916-1926 (2017).

75. Zugaro, L. et al. Treatment of osteolytic solitary painfu osseous metastases with radiofrequency ablation or cryoablation: a retrospective study by propensity analysis. Oncol. Lett. 11, 1948-1954 (2016).

76. Zołnierek, J. et al. Efficacy of targeted therapy in patients with renal cell carcinoma with pre-existing or new bone metastases. J. Cancer Res. Clin. Oncol. 136 371-378 (2010)

77. Kalra, S. et al. Outcomes of patients with metastatic renal cell carcinoma and bone metastases in the targeted therapy era. Clin. Genitourin. Cancer 15 363-370 (2017)

78. Maita, S. et al. Antitumor effect of sunitinib against skeletal metastatic renal cell carcinoma through 
inhibition of osteoclast function. Int. J. Cancer 130 677-684 (2012)

79. Choueiri, T. K. et al. Cabozantinib versus everolimus in advanced renal cell carcinoma (METEOR): final results from a randomised, open-label, phase 3 trial. Lancet Oncol. 17, 917-927 (2016).

80. Fioramonti, M. et al. Cabozantinib targets bone microenvironment modulating human osteoclast and osteoblast functions. Oncotarget 8, 20113-20121 (2017).

81. Motzer, R. J. et al. Nivolumab versus everolimus in advanced renal-cell carcinoma. N. Engl. J. Med. 373, 1803-1813 (2015)

82. Saad, F. \& Lipton, A. Zoledronic acid is effective in preventing and delaying skeletal events in patients with bone metastases secondary to genitourinary cancers. BJU Int. 96, 964-969 (2005).

83. Henry, D. H. et al. Randomized, double-blind study of denosumab versus zoledronic acid in the treatment of bone metastases in patients with advanced cance (excluding breast and prostate cancer) or multiple myeloma. J. Clin. Oncol. 29, 1125-1132 (2011).

84. Ripamonti, C I et al Management of cancer pain ESMO clinical practice guidelines. Ann. Oncol. 23 (Suppl. 7), vii139-154 (2012).

85. Roelofs, A. J. et al. Bisphosphonates: molecular mechanisms of action and effects on bone cells, monocytes and macrophages. Curr. Pharm. Des. 16 2950-2960 (2010).

86. Rosen, L. S. et al. Zoledronic acid versus placebo in the treatment of skeletal metastases in patients with lung cancer and other solid tumors: a phase III, double-blind, randomized trial-the Zoledronic Acid Lung Cancer and Other Solid Tumors Study Group. J. Clin. Oncol. 21, 3150-3157 (2003).

87. Lipton, A. et al. Skeletal complications in patients with bone metastases from renal cell carcinoma and therapeutic benefits of zoledronic acid. Clin. Cancer Res. 10, 6397S-403S (2004).

88. Tunn, U. W. et al. Positive effects of zoledronate on skeletal-related events in patients with renal cell cancer and bone metastases. Can. J. Urol. 19 , 6261-6267 (2012).

89. McKay, R. R. et al. Prognostic significance of bone metastases and bisphosphonate therapy in patients with renal cell carcinoma. Eur. Urol. 66, 502-509 (2014).

90. Thompson, R. N. et al. Atypical femoral fractures and bisphosphonate treatment: experience in two large United Kingdom teaching hospitals. J. Bone Joint Surg. Br. 94, 385-390 (2012).

91. Fusco, V. et al. Osteonecrosis of the jaw in patients with metastatic renal cell cancer treated with bisphosphonates and targeted agents: results of an Italian multicenter study and review of the literature. Clin. Genitourin. Cancer 13, 287-294 (2015).

92. Henry, D. et al. Delaying skeletal-related events in a randomized phase 3 study of denosumab versus zoledronic acid in patients with advanced cancer: an analysis of data from patients with solid tumors. Support Care Cancer 22, 679-687 (2014).
93. Lipton, A. et al. Superiority of denosumab to zoledronic acid for prevention of skeletal-related events: a combined analysis of 3 pivotal, randomised, phase 3 trials. Eur. J. Cancer 48, 3082-3092 (2012)

94. Saad, F. et al. Incidence, risk factors, and outcomes of osteonecrosis of the jaw: integrated analysis from three blinded active-controlled phase III trials in cancer patients with bone metastases. Ann. Oncol. 23 1341-1347 (2012).

95. Khan, A. A. et al. Diagnosis and management of osteonecrosis of the jaw: a systematic review and international consensus. J. Bone Miner. Res. 30, 3-23 (2015).

96. Kijima, T. et al. Radiotherapy to bone metastases from renal cell carcinoma with or without zoledronate. BJU Int. 103, 620-624 (2009).

97. Takeda, N. et al. Zoledronic acid enhances the effect of radiotherapy for bone metastases from renal cell carcinomas: more than a 24-month median follow-up. J. Orthop. Sci. 17, 770-774 (2012).

98. Kijima, T. et al. Zoledronic acid sensitizes renal cell carcinoma cells to radiation by downregulating STAT 1 . PLOS One 8, e64615 (2013).

99. Staehler, M. et al. Simultaneous anti-angiogenic therapy and single-fraction radiosurgery in clinically relevant metastases from renal cell carcinoma. BJU Int. 108, 673-678 (2011).

100. Lutz, S. et al. Palliative radiotherapy for bone metastases: an ASTRO evidence-based guideline. Int. J. Radiat. Oncol. Biol. Phys. 79, 965-976 (2011).

101. Fischer, M. \& Kampen, W. U. Radionuclide therapy of bone metastases. Breast Care (Basel) 7, 100-107 (2012).

102. Serafini, A. N. et al. Palliation of pain associated with metastatic bone cancer using samarium-153 lexidronam: a double-blind placebo-controlled clinical trial. J. Clin. Oncol. 16, 1574-1581 (1998).

103. Roque, I. F. M. et al. Radioisotopes for metastatic bone pain. Cochrane Database Syst. Rev. 7 , CD003347 (2011)

104. Owen, R. J. Embolization of musculoskeletal bone tumors. Semin. Intervent. Radiol. 27, 111-123 (2010).

105. Forauer, A. R. et al. Selective palliative transcatheter embolization of bony metastases from renal cell carcinoma. Acta Oncol. 46, 1012-1018 (2007).

106. Pazionis, T. J. et al. Embolization of hypervascular bone metastases reduces intraoperative blood loss: a case-control study. Clin. Orthop. Relat. Res. 472 3179-3187 (2014).

107. Pellerin, O. et al. Management of painful pelvic bone metastasis of renal cell carcinoma using embolization, radio-frequency ablation, and cementoplasty: a prospective evaluation of efficacy and safety. Cardiovasc. Intervent. Radiol. 37, 730-736 (2014).

108. European Society for Medical Oncology. SOPs/ instructions for authors and templates for standard ESMO clinical practice guidelines (CPGs) and ESMO MCBS scores. ESMO https://www.esmo.org/content/ download/77789/1426712/file/ESMO-Clinical-PracticeGuidelines-Standard-Operating-Procedures.pdf (2018).

\section{Acknowledgements}

This Expert Consensus Document was funded by the International Kidney Cancer Coalition (IKCC). The authors thank A. Luetke (medinform, Ratekau, Germany) for editorial support on behalf of the IKCC.

\section{Author contributions}

V.G., C.v.F., and M.S. researched data for the article. V.G., B.E., A.B., A.F., T.G., H.R.D., R.H.G., C.v.F., A.G., and M.S. made substantial contributions to discussion of the article contents. V.G., A.B., A.F., T.G., T.D., M.P., H.R.D., R.H.G., C.v.F., A.G., and M.S. wrote the manuscript. All authors reviewed and/or edited the manuscript before submission.

\section{Competing interests}

V.G. has participated in advisory boards for Bristol Myer Squibb (BMS), Eisai, Ipsen, Novartis, Pfizer, and Roche, has received honoraria for compensation from BMS, Eisai, Ipsen, Novartis, Pfizer, and Roche, and has received travel grants from BMS, MSD Merck, Novartis, and Pfizer. B.E. has received honoraria and/or travel grants from Pfizer. Uronauten receives no grants from the pharmaceutical industry. A.B. has participated in advisory boards for BMS, Ipsen, Novartis, Pfizer, and Roche/Genentech. A.F. has received honoraria and/or travel grants from Bayer, Ipsen, and Pfizer. R.H.G. has participated in advisory boards for Ipsen and Pfizer and has received travel grants from Ipsen and Pfizer. A.G. has received honoraria and/or travel grants from Bayer, Novartis, and Pfizer. M.S. participated in advisory boards for AVEO, BMS, Eisai, EUSA Pharma, Exelixis, Ipsen, Novartis, Peloton, Pfizer, and Roche/Genentech, has received travel grants from Bayer, BMS, Eisai, Ipsen, Novartis, and Pfizer, and has received research grants from AVEO, BMS, Eisai, Exelixis, Ipsen, Novartis, Pfizer, and Roche/Genentech. The International Kidney Cancer Coalition (IKCC) receives grants from Global Offices of Ipsen/Exelixis, Merck/MDS, BMS, Pfizer, Novartis, and Eisai. T.G., T.D., M.P., H.R.D., K.A.G., C.v.F., and A.M. declare no competing interests.

\section{Publisher's note}

Springer Nature remains neutral with regard to jurisdictional claims in published maps and institutional affiliations.

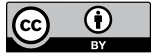

Open Access This article is licensed under a Creative Commons Attribution 4.0 International License, which permits use, sharing, adaptation, distribution and reproduction in any medium or format, as long as you give appropriate credit to the original author(s) and the source, provide a link to the Creative Commons license, and indicate if changes were made. The images or other third party material in this article are included in the article's Creative Commons license, unless indicated otherwise in a credit line to the material. If material is not included in the article's Creative Commons license and your intended use is not permitted by statutory regulation or exceeds the permitted use, you will need to obtain permission directly from the copyright holder. To view a copy of this license, visit http://creativecommons.org/licenses/by/4.0/. 